\title{
A BIO-INSPIRED CONDYLAR KNEE JOINT FOR KNEE PROSTHETICS
}

\author{
A.C. ETOUNDI ${ }^{1}$, R.J. LOCK ${ }^{1}$, R. VAIDYANATHAN ${ }^{2} \&$ S.C. BURGESS ${ }^{1}$ \\ ${ }^{1}$ University of Bristol, Bristol, United Kingdom. \\ ${ }^{2}$ Imperial College, London, United Kingdom.
}

\begin{abstract}
This paper presents a novel bio-inspired condylar prosthetic knee joint developed at the University of Bristol. The bio-inspired condylar joint mimics the structure and biomechanics of the human knee joint. The joint contains an inverted parallelogram four-bar mechanism combined with a cam mechanism. The joint has a favourable mechanical advantage compared with a hinge joint. The joint is also compact and robust. An adultsized prototype joint has been designed and tested. The prototype joint contains a long cable for the ligaments with a mechanism for adjusting preload. Compared with other prosthetic joints, the condylar joint has the advantages that it is simple and closely mimics human biomechanics. This paper presents the design of the new artificial knee joint and some of the test results. The joint can be used in artificial legs and also for knee implants. A rapid prototyping procedure is also presented that enables a custom-sized prosthetic knee joint to be made very quickly and from just a few key dimensions. This process has the potential to improve the quality of surgical implants.

Keywords: Bio-inspired hinge joint, cruciate ligaments, four-bar mechanism, moving centre of rotation, prosthetic joint, rapid prototyping.
\end{abstract}

\section{INTRODUCTION}

One of the first recorded artificial knee joints was that produced by Ambroise Pare, a French surgeon, as part of an artificial leg in the sixteenth century. The first implanted knee replacements were carried out in 1972 by John Insall, an English surgeon living in New York, who implanted a prosthesis to replace the three surfaces of the knee - femur, tibia and patella (knee cap) [1]. At present, there are around 5,000 leg amputees per year in the UK. In addition, there are 70,000 knee replacements carried out each year in the UK. Artificial knee joints are an important medical device that enables many people to maintain walking and running functions. Ideally, a prosthetic knee joint for leg amputees or knee implants should (i) mimic the motion of a human knee, (ii) fit within the envelope of a human knee, (iii) be lightweight, (iv) be mechanically efficient and (v) be shock absorbing. These are very difficult attributes to achieve because of the tight space limitations of the human knee and because of the complex biomechanical movement of the knee joint $[2,3]$.

Prosthetic knee joints generally contain four-bar mechanisms in order to produce a moving centre of rotation as with the human knee. Some common designs are shown in Fig. 1. There are two main categories of control of prosthetic knee joints - microprocessor control and mechanical control. Microprocessor control involves the use of an electronic unit, which evaluates and makes internal adjustments to control the motion of the knee. Mechanical control involves the use of a mechanical hinge, which is automatically controlled by a four-bar mechanism.

Biomechanical variables, such as a moving centre of rotation, have an important effect on the energy requirements of walking and running in able-bodied people [4]. In the literature, prosthetic knee joints have been classified according to the level of complexity [5]. The most complex of these is the polycentric prosthetic knee (four-bar knee), which has its instantaneous centre of rotation (ICR) located at the intersection of the anterior and posterior links that are located above the knee joint as shown in Fig. 1. While the ICR moves anteriorly to the ground reaction force, resulting in an 


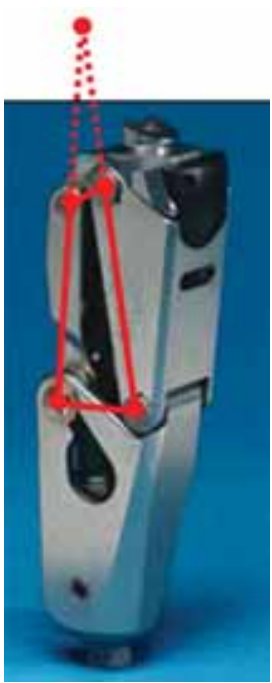

(A)

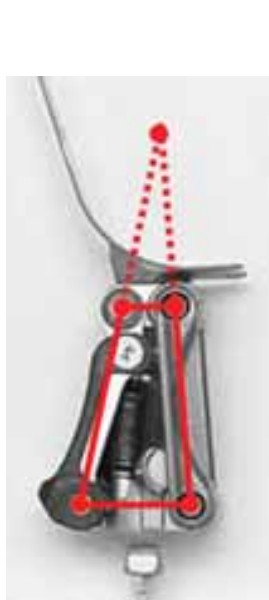

(B)

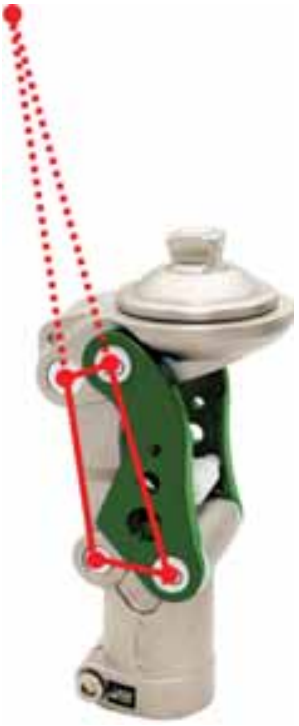

(C)

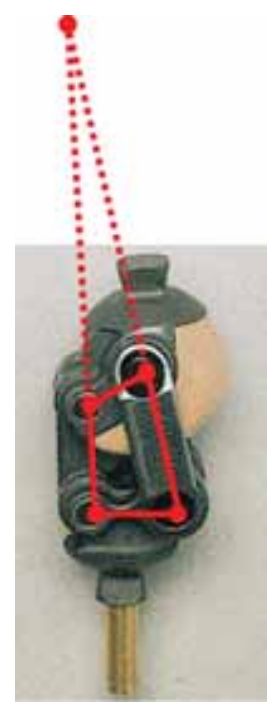

(D)

Figure 1: Instant centres of rotation for several polycentric prosthetic knees: (A) [6], (B) and (C) [7] and (D) [8].

increase in the knee extension moment, the stability of the prosthesis is maintained. Hence, the fourbar configuration enables an optimisation of the swing and stance phase during locomotion and an increase in knee stability.

This paper presents a bio-inspired condylar knee joint for prosthetic applications using a crossed four-bar mechanism (inverted parallelogram mechanism), which has the same advantages of a parallelogram including compactness, high stiffness and locking in the upright position.

\section{BIOMECHANICS OF THE HUMAN KNEE JOINT}

\subsection{Biomechanics of the knee joint}

The human knee joint is more complex than a hinge joint because during locomotion, rolling and sliding occur at the joint interface. There are three different types of structures defining the knee joint behaviour: static (geometry and anatomy of the joint surfaces), active (muscle tensions) and passive

(ligaments). The knee joint comprises the articulation of the femur over the tibia (tibiofemoral joint). The main functions of the knee are to absorb and transmit the load while allowing rotation of the joint. The femur has a convex surface and the tibia a matching concave surface, which allows the bones to roll over each other. Straightening of the leg is called extension, whereas bending of the leg is called flexion.

The motion of the knee is commonly modelled as a planar four-bar mechanism as shown in Fig. 2. The motion of the knee is guided by the anterior and posterior cruciate ligaments (ACL and PCL). The crossed four-bar mechanism is an inverted parallelogram mechanism. At different knee flexion angles, the ICR is located at the point at which the ACL and PCL cross. The centre of rotation follows an elliptical pathway ('J' curve) [9] and moves typically by around $2 \mathrm{~cm}$ in a healthy 


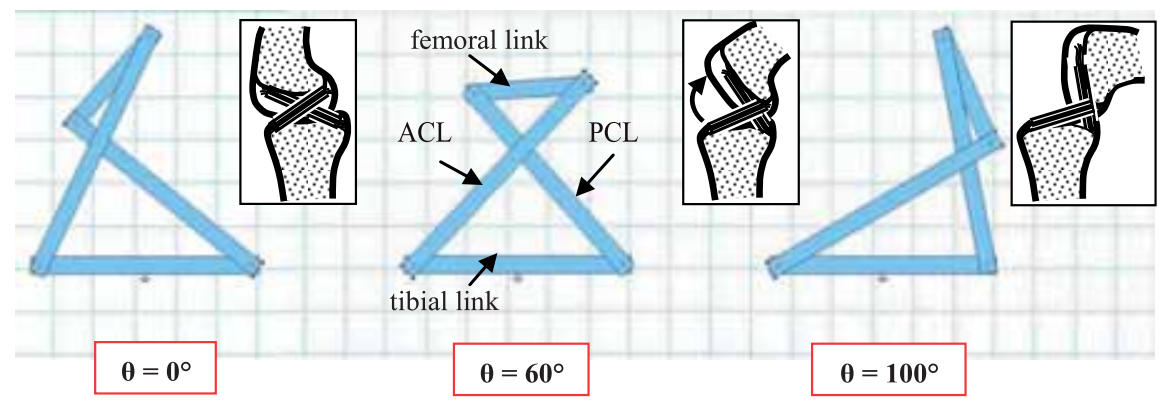

Figure 2: The four-bar mechanism of the human knee joint.

adult knee joint [10]. The motion of the four-bar mechanism is compatible with the cam profile of the condylar bones.

Another important feature of the human knee joint is that the joint locks in an upright position. This reduces the work performed by the quadriceps muscles during standing [11]. The supporting structures of the mammalian knee joint such as ligaments, menisci and articular surfaces (femoral condyle and tibial plateau) help guide and provide stability during the joint's motion [12-14].

\subsection{Key design features of knee with biomimetic potential}

The key features of the human knee joint that are of interest for a bio-inspired prosthetic joint design are:

- Separation of structural (compression joint) and kinematic (four-bar mechanism) functions.

- Curved (condylar) joint giving high conformity and, therefore, high stiffness and strength.

- Moving centre of rotation giving potential for optimal mechanical advantage.

- Simplicity of design giving potential for compactness and robustness.

- Locking in upright position.

By having a separation of functions, it is easier to achieve optimisation of design because the two mechanisms can be optimised fully for their particular function. The compression joint is optimal because it avoids bending moments by forming a simple compression joint. In contrast, joints like the hip joint have high bending moments because of the offset between the ball and the main structural members. Whereas the hip joint is vulnerable to failure due to impact bending loads, the knee joint is relatively robust. A component is generally more structurally efficient when bending moments are minimised because bending moments are a type of force amplification $[15,16]$. The simple compression joint of the knee leads to it being a very compact and optimal joint.

\section{BIOMECHANICS OF WALKING, RUNNING AND SQUATTING}

An understanding of knee kinematics during daily life activities (walking, running and squatting) is necessary to be able to design an effective prosthetic knee. There are several terms that are commonly used for characterising gait that are unified among researchers. A gait cycle is usually defined as the movements and events that occur between successive heel contacts of the same foot $[17,18]$. The gait cycle has two phases: stance (foot on the ground) and swing (foot off the ground). These two states vary depending on the activity, as shown in Fig. 3. While normal walking is defined in 


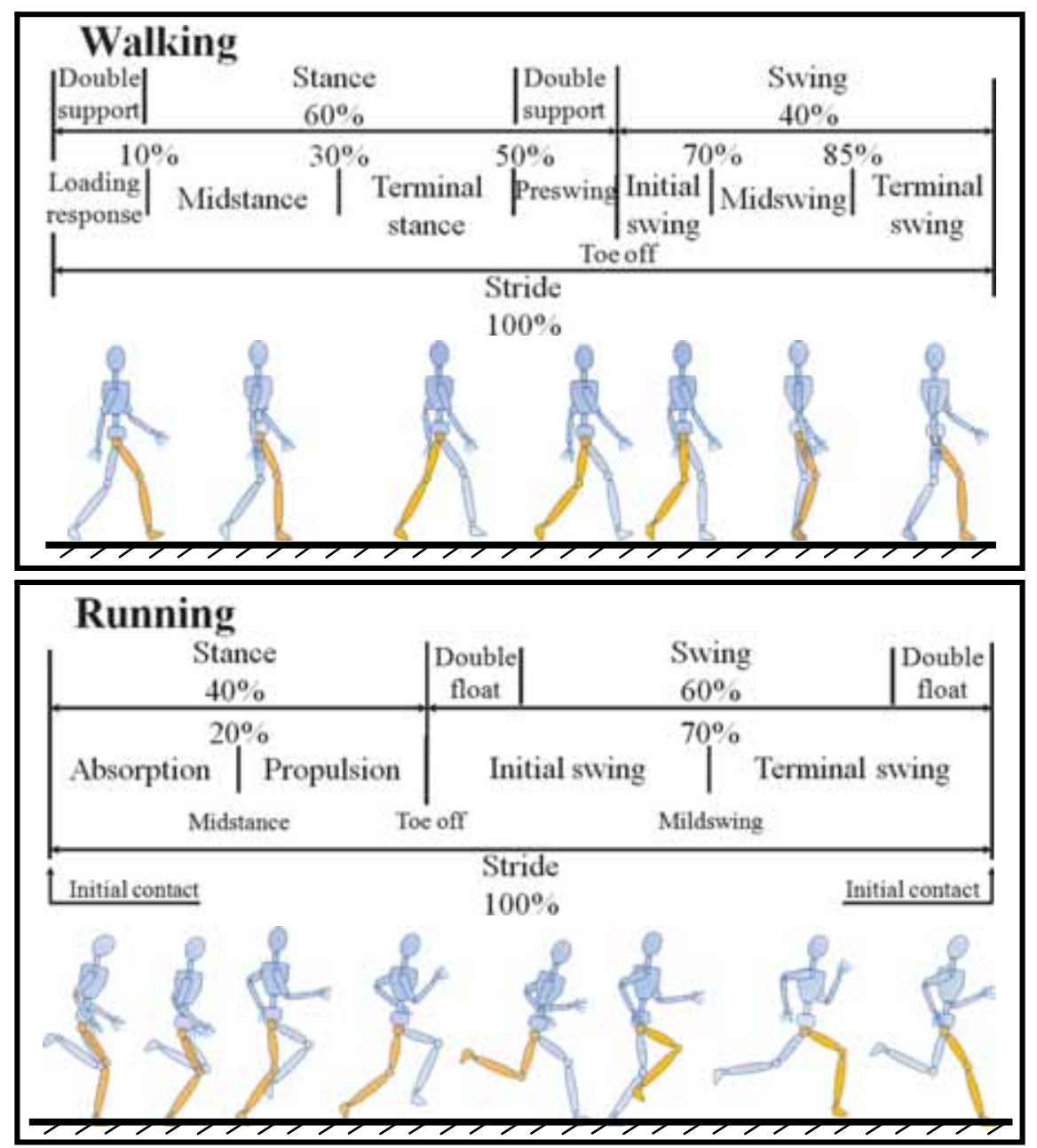

Figure 3: Gait cycle terminology used for walking and running adapted from [17].

terms of double support, two limbs in contact with the ground, running is identified by its double float period, neither limbs in contact with the ground.

For athletes, the squat exercise enhances athletic performances while minimising the risk of injuries [19]. The squat exercise is also commonly used in knee rehabilitation because it is a weight-bearing exercise whereby the patient utilises his own body weight [20,21]. There are usually two types of squat, the half squat or full squat, depending on the degree of knee flexion. The half squat is when the body stands upright and is gradually flexed until the thighs are parallel with the ground (approximately between $0^{\circ}$ and $90^{\circ}$ of knee flexion). The deep squat involves squatting down until the posterior thighs and shank make contact with each other [22]. Throughout all these knee movements, the passive characteristics of the anterior-posterior motion are related to the shape of the articular surfaces and ligament function [23]. Thus, the typical activities of daily living show that knee motion is activity dependent and requires a complex set of moving parts acting together, which 


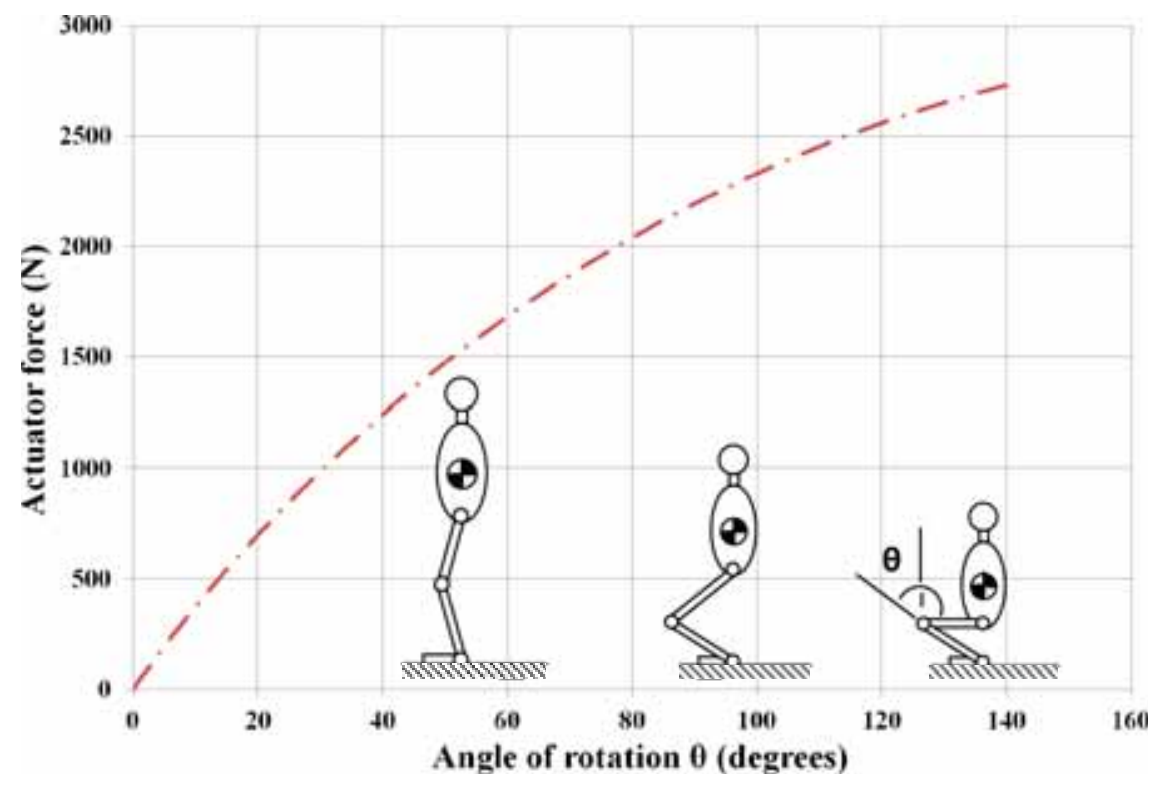

Figure 4: The force required for a deep squatting motion for the four-bar hinge.

can accept, transfer and dissipate loads generated at the ends of the long mechanical lever arms of the femur and the tibia. Figure 4 shows a deep squat with a flexion angle of $140^{\circ}$.

\section{EXISTING PROSTHETIC KNEE JOINT DESIGN FOR ARTIFICIAL LEGS}

Table 1 shows different existing prosthetic knee joint designs together with the condylar joint with their respective advantages and drawbacks. The manual locking knee locks in the straight position during walking and can be manually unlocked in the sitting position by pulling a cable. The stance control knee contains a weight-activated friction brake preventing the knee from bending and buckling when the amputee puts weight on the prosthesis. The polycentric knee, called a four-bar knee, is used by a wide range of amputees due to its complex mechanism, which allows flexibility in stability settings and variable speeds. Pneumatic and hydraulic knees are fitted with cylinders, containing air or fluid, respectively, which control the speed of the knee flexion. Microprocessor knees are 'smart' knees because, due to their active control (microcontroller), they assess the forces acting on the joint and can quickly accommodate for speed, stability and internal adjustments.

\section{THE NOVEL CONDYLAR KNEE JOINT}

Figure 5 shows the prototype model of the bio-inspired condylar hinge joint. The design mimics the curved profiles of the human knee joint in order to achieve the benefits of high conformity and high stiffness and strength. The design also copies the four-bar motion of the ligaments. However, the ligaments are positioned differently to a human knee. Instead of locating one set of crossed members in the centre of the joint as with the human knee joint, the design has two sets of cruciate ligaments with one set on each side of the joint. This provides stability and alleviates the need for additional ligaments to surround the joint.

The femur and tibia components taper down to a 35-mm circular section, which is approximately equal in size to human bone. The femur component has a white nylon end cap in order to provide an 
Table 1: Different prosthetic knee designs for amputees.

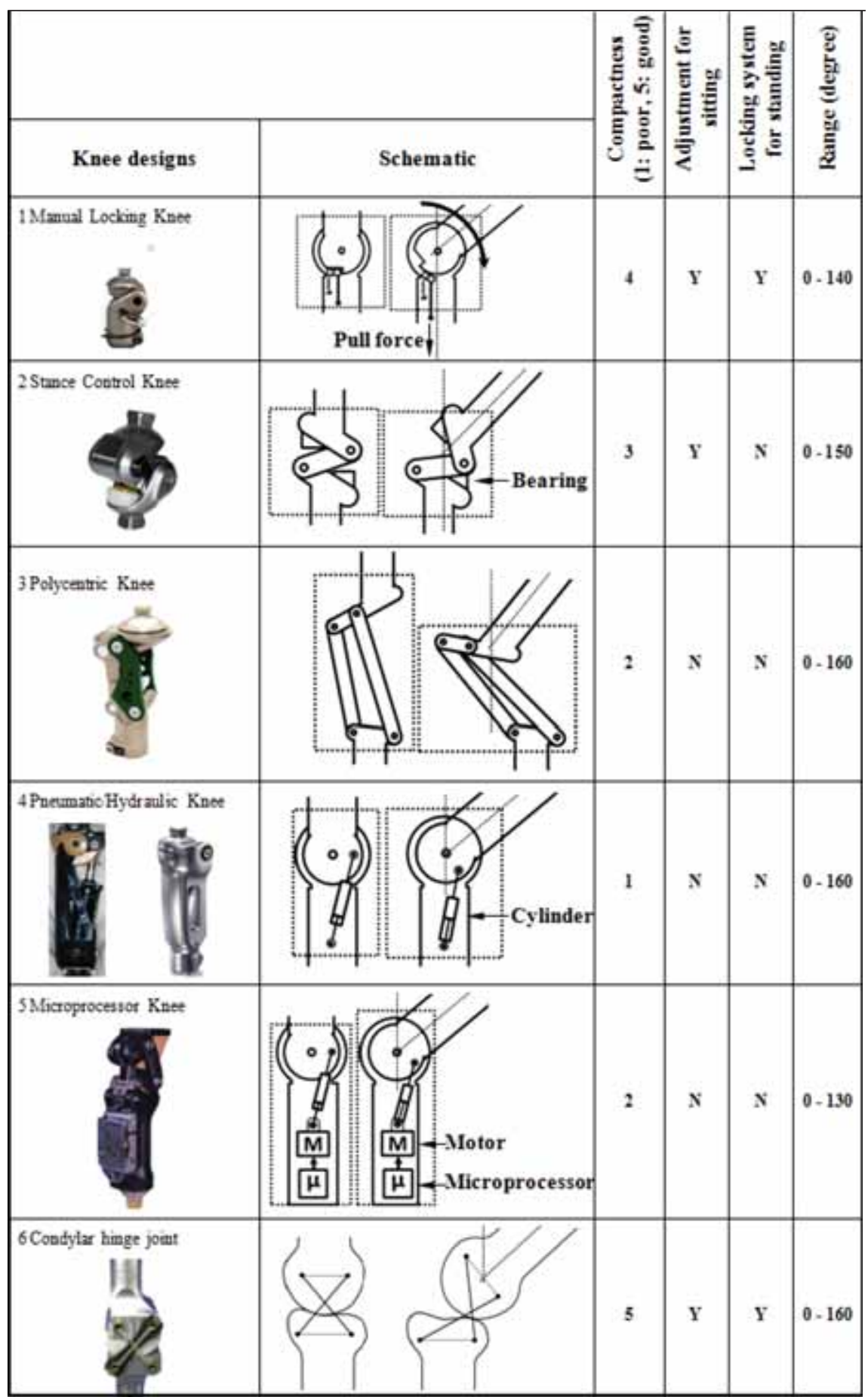




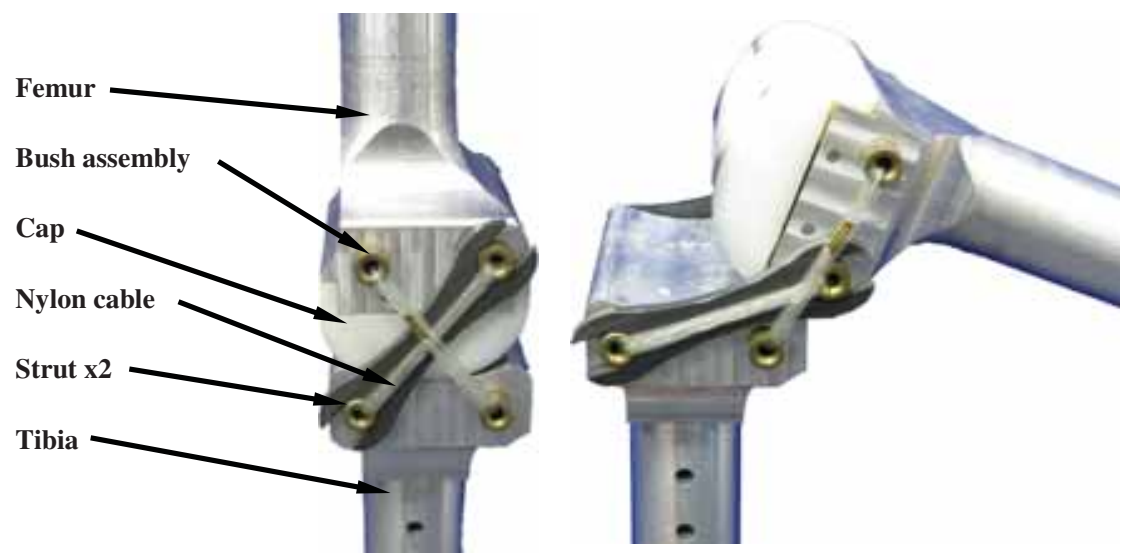

Figure 5: Prototype condylar hinge joint.

appropriate material for sliding and rolling against the metal tibia. The curvature of the femur and tibia components was designed to match the moving centre of rotation of the four-bar mechanism. The prototype gives $160^{\circ}$ of smooth motion whilst maintaining joint integrity. Another difference from the human knee joint is that the cruciate ligaments are not separate ligaments but one continuous ligament that is threaded through the joint. Both the tibia and femur components have two holes drilled across their whole length with brass brushes inserted, as shown in Fig. 5. There are a number of advantages of having a continuous cable threaded through the joint:

- The cable has no need for anchor pivot points.

- The cable is only one component.

- The cable holds the joint in the lateral position.

- The upper and lower condyles have no cut-out.

Early prototype testing showed that the joint is very sensitive to the level of tension in the cable. If the tension is too high the friction is high, but if the tension is too low the knee is unstable. A reliable tension was achieved by creating compliance in the cable system. This was accomplished by having a single long continuous cable threaded through each tension sleeve. In addition, the cable consisted of a single fine wire that was threaded through the joint 11 times.

By having one continuous cable, the length of the cable is very long. The total cable length in the prototype is $3.124 \mathrm{~m}$. Over this length, it was feasible to create a compliant cable that could have adjustable preload. Adjustment of preload was achieved through the use of a threaded joint in the brass bushes that adjusted their length. Changes in bush length change the cable length and hence cable tension. The individual cable wire was made from monofilament nylon of $0.65-\mathrm{mm}$ diameter. It was joined using specially designed crimps. The cable assembly was pre-tightened to give a tension of $3.7 \mathrm{~N}$. The cable assembly has a breaking strength of $2500 \mathrm{~N}$.

Experimental testing on an early prototype showed that when the joint rotated through more than $60^{\circ}$ from the vertical, the bearing surfaces slid past one another thus creating instability in the joint. This slippage was due to: (1) lack of muscular action to hold the joint together in the artificial joint and (2) lack of menisci to withstand shear forces and to distribute tensile and compressive loads. This issue was addressed through the use of a compression bar across one diagonal of each four-bar mechanism as shown in Fig. 5. 
The biomechanical design of the artificial knee is very similar to a knee joint in the plain of motion [3]. It should be noted that the condylar hinge requires the extensor and flexor actuator to move through different length ratios as the mechanical advantage changes.

\section{PERFORMANCE}

\subsection{Test rig}

A test rig was designed to simulate a 'squat' or 'leg press' situation while applying a load on the knee. This was chosen as the knee moves through a large angle of rotation and the loading is constant (equal to body weight). Initial tests at low load levels were carried out in order to allow the joint to run in. The motor was capable of cyclically loading the joint at a rate of $20 \mathrm{rpm}$, which corresponds to 20 squats per minute. It should be noted that actuation was achieved by directly driving the tibia component and not through tendons in the knee joint. The rig was used to apply 50,000 cycles under load. The rotation of the knee in the sagittal plane during normal walking goes up to $65^{\circ}$ and corresponds to a distance travelled of $1 \mathrm{~m}$. Therefore, the tests correspond to a distance travelled approximately $100 \mathrm{~km}$. The performance of the joint was re-assessed by measuring the friction and stiffness of the joint as well as visually inspecting the bearing surfaces.

\subsection{Life testing with 10 and $20 \mathrm{~kg}$ loads}

Life testing was carried out in five stages as shown in Table 2.

Figure 6 shows the results of frictional tests carried out after the five sets of tests. The reason for doing the frictional tests was to see if pre-tension had been lost due to wear. The results show that the frictional torque profile was reasonably consistent throughout the tests, indicating that pretension was consistent and that wear was minimal. Visual inspection also showed that wear was minimal.

\section{CUSTOMISATION OF KNEE GEOMETRY THROUGH RAPID PROTOTYPING}

Even though prosthetic knee joints have been greatly improved in quality over the last few decades [6-8], there is still a need for customisation of knee implant geometry to suit individual patients. At present, prosthetic knee sizes are generally limited to small, medium and large [24, 25]. However, there is great variability in size and shape amongst men and women [26]. For example, the width of a male knee can vary between 6 and $8 \mathrm{~cm}$ and the depth varies between 5 and $7.5 \mathrm{~cm}$ [27]. Whilst the standard sizes of small, medium and large may suit some people, these sizes are not ideal for others who do not fit these standard sizes.

Table 2: Test program.

\begin{tabular}{lcc}
\hline Test number & Number of cycles & Loading $(\mathrm{kg})$ \\
\hline 1 & 15,000 & 10 \\
2 & 10,000 & 10 \\
3 & 5,000 & 20 \\
4 & 10,000 & 20 \\
5 & 10,000 & 20 \\
\hline
\end{tabular}




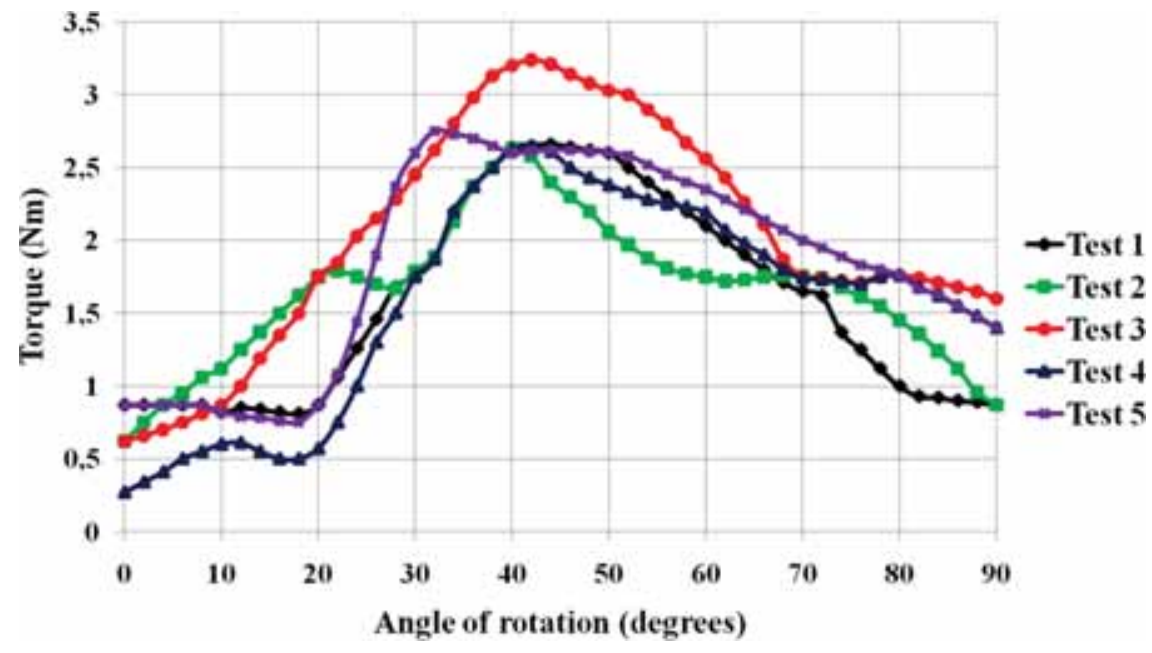

Figure 6: Changes in friction during test program.

One strategy for customising knee size is to take a set of X-rays of a patient's knee to find out their size and then manufacture a custom-sized knee before surgery. However, it is difficult to take accurate measurements with X-rays and some of the three-dimensional (3D) knee features such as the condyle interface can be hidden from X-rays. Another strategy for the customisation of knee size is to use rapid prototyping technology. Rapid prototyping technology has been proposed for the rapid construction of exoskeletons for hand rehabilitation [28]. It has also been used for handheld devices, small electronic devices, aerospace prototyping and, most recently, biomedical devices [29]. The concept is that when a surgeon opens up the knee joint for replacement surgery, some simple measurements are carried out and a custom-sized prosthetic knee is created.

In order to work best, rapid prototyping technology would have to be able to manufacture and assemble in a time which is well within the operating time for a knee replacement. The operating time to replace a knee is the order of 70-90 $\min$ [30-32]. Therefore, to be useful, a knee produced by rapid prototyping would need to be made within around $50 \mathrm{~min}$. The flow chart in Fig. 7 shows the steps involved and the time that each takes for making the rapid prototyping joint.

The following measurements of the knee are required from the patient:

i. Knee's envelope (height, width and depth).

ii. Femur profile (major and minor axis of the elliptical condyle).

iii. Ligament dimensions (position of anchor points and lengths).

These measurements are imported into the MATLAB ${ }^{\circledR}$ kinematic model and then a program is run to calculate the shape of the prosthetic knee and positions of the ligament anchor points. The results are exported to Microsoft Excel and are then imported into Autodesk Inventor Professional ${ }^{\circledR}$ 2012, which then creates a 3D solid model of the knee. Autodesk Inventor Professional converts the 3D solid model into an STL file, which is the standard format for rapid prototyping machines, and then transfers the file to the rapid prototyping machine that can produce the desired model.

We carried out one demonstration of the rapid prototype process using a Stratasys ${ }^{\circledR}$ FDM $400 \mathrm{mc}$ rapid prototype machine. It should be noted that the manufacturing time here is for the 
fastest rapid prototyping machines and for parallel production. The input dimensions were the knee's envelope (height, width and depth), the femur (minor axis and major axis) and the ligament lengths (anterior and posterior). These measurements correspond to an average male adult sized knee. The outputted components are shown in Fig. 8. An estimated assembly time of 5 min has been assumed.

\section{OUTPUT}

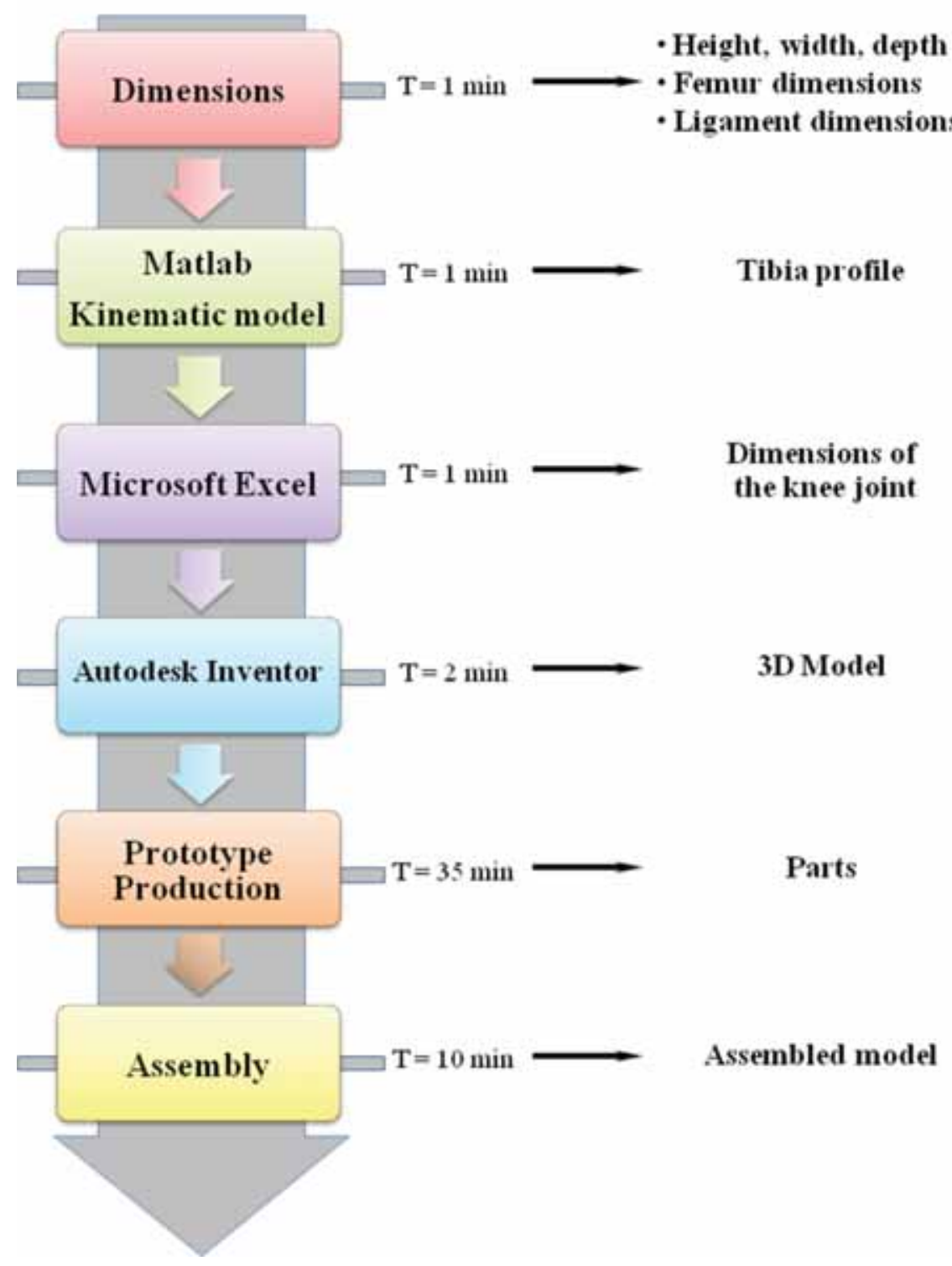

Figure 7: Flow chart of the rapid prototyping knee joint $\left(\mathrm{T}_{\mathrm{TOTAL}}=50 \mathrm{~min}\right)$. 

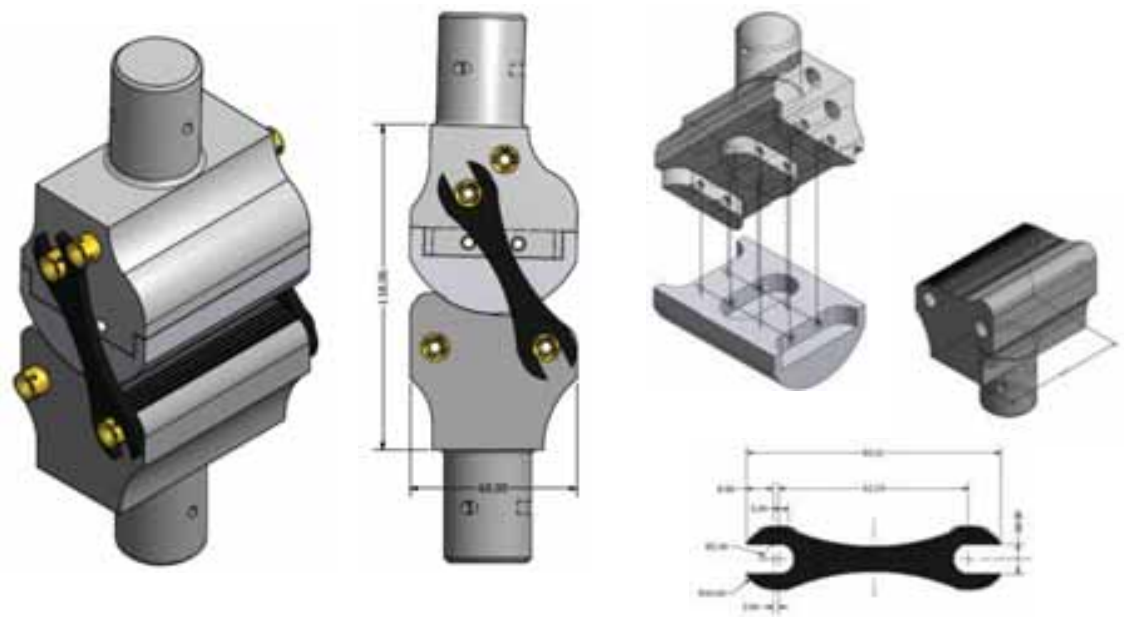

(A)
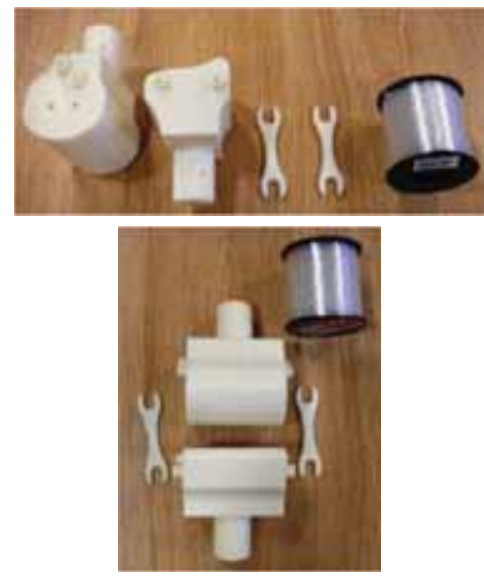

(B)

Figure 8: (A) Drawing of the prototype knee joint from Autodesk Inventor Professional ${ }^{\circledR} 2012$. (B) Rapid prototyped knee joint composed by the femur, tibia, struts (2) and nylon ropes.

\section{CONCLUSIONS}

This paper has presented a bio-inspired condylar design of knee joint for prosthetic applications. The joint mimics the condylar surfaces of the femur and tibia bones in the human knee joint and also mimics the four-bar motion of the cruciate ligaments. The bio-inspired design has the same desirable features of a human knee joint including a moving centre of rotation, high strength, high stiffness, compactness and locking in the upright position. The bio-inspired design could be used for artificial legs or for knee implants. Experimental tests have verified the kinematic, stiffness and life performance of the joint. A rapid prototyping procedure has also been presented that enables a custom-sized prosthetic knee joint to be made very quickly and from just a few key dimensions. This process has the potential to improve the quality of surgical implants. A key feature of the design is its simplicity and similarity to the mammalian knee joint. 


\section{REFERENCES}

[1] Murnaghan, J.M. \& Hamer, A.J., Hip and knee replacement. Orthopaedic Surgery: Lower Limb, 28(10), pp. 508-513, 2010.

[2] Michael, J.W., Prosthetic knee mechanisms. Physical Medicine \& Rehabilitation: State of the Art Reviews, 8, pp. 147-164, 1994.

[3] Etoundi, A.C., Vaidyanathan, R. \& Burgess, S.C., A bio-inspired condylar hinge joint for mobile robots, Proceedings of the IEEE International Conference on Intelligent Robots and System, ed. N.M. Amato, IEEE/RSJ: San Francisco, pp. 4042-4047, 2011.

[4] Buckley, J.G., Spence, W.D. \& Solomonidis, S.E., Energy cost of walking: comparison of "intelligent prosthesis" with conventional mechanism. Archives of Physical Medicine and Rehabilitation, 78, pp. 330-333, 1997. doi: http://dx.doi.org/10.1016/S0003-9993(97)90044-7

[5] Radcliffe, C. W., Above-knee prosthetics. Prosthetics and Orthotics International, 1, pp. 146160, 1977.

[6] ST\&G Prosthetics Product Catalog 2010, available at http://www.fabtechsystems.com/skin1/ images/pdfs/STNGcatalog_usa_web.pdf

[7] Otto Bock Modular Knee Joints Catalog 2003, available at http://www.ottobock.ca/cps/rde/ xbcr/ob_us_en/knee_joints.pdf

[8] Beijing P\&O Technique Center Catalog 2008, available at http://www.bjpotc.com/ upload/66304317.pdf

[9] Fu, F.H., Harner, C.D., Johnson, D.L., Miller, M.D. \& Woo, S.L.Y., Biomechanics of knee ligaments. Journal of Bone \& Joint Surgery, 75, pp. 1716-1727, 1993.

[10] Montgomery, S.C., Moorehead, J.D., Davidson, J. S., Lowe, D. \& Dangerfield, P.H., A new technique for measuring the rotational axis pathway of a moving knee. The Knee, 5(4), pp. 289-295, 1998. doi: http://dx.doi.org/10.1016/S0968-0160(97)10029-1

[11] Rajendran, K., Mechanism of locking at the knee joint. Journal of Anatomy, 143, pp. 189-194, 1985.

[12] Wilson, D.R., Feikes, J.D. \& O'Connor, J.J., Ligaments and articular contact guide passive knee flexion. Journal of Biomechanics, 31, pp. 1127-1136, 1998. doi: http://dx.doi.org/10.1016/ $\underline{\text { S0021-9290(98)00119-5 }}$

[13] Moglo, K.E. \& Shirazi-Adl, A., Cruciate coupling and screw-home mechanism in passive knee joint during extension-flexion. Journal of Biomechanics, 38, pp. 1075-1083, 2005. doi: http:// dx.doi.org/10.1016/j.jbiomech.2004.05.033

[14] Wilson, D.R., Feikes, J.D., Zavatsky, A.B. \& O'Connor, J.J., The components of passive knee movement are coupled to flexion angle. Journal of Biomechanics, 33, pp. 465-473, 2000. doi: http://dx.doi.org/10.1016/S0021-9290(99)00206-7

[15] Imam, M.H. \& Al-Shihri, M., Optimum topology of structural supports. Computers \& Structures, 61, pp. 147-154, 1996. doi: http://dx.doi.org/10.1016/0045-7949(96)00087-9

[16] Wang, D., Optimal design of structural support positions for minimizing maximal bending moment. Finite Elements in Analysis and Design, 43, pp. 95-102, 2006. doi: http://dx.doi.org/ 10.1016/j.finel.2006.07.004

[17] Ounpuu, S., The biomechanics of walking and running. Clinics in Sports Medicine, 13, pp. 843-863, 1994.

[18] Perry, J., Normal and pathologic gait. Atlas of Orthotics: Biomechanical Principles and Application, 2nd edn., American Academy of Orthopaedic Surgeons (AAOS): St Louis, pp. 76-111, 1985.

[19] Shelbourn, K.D. \& Nitz, P., Accelerated rehabilitation after anterior cruciate ligament reconstruction. The American Journal of Sports Medicine, 18, pp. 292-299, 1990. doi: http:// dx.doi.org/10.1177/036354659001800313 
[20] Ohkoshi, Y., Yasuda, K., Kaneda, K., Wada, T. \& Yamanaka, M., Biomechanical analysis of rehabilitation in the standing Position. The American Journal of Sports Medicine, 19, pp. 605-611, 1991. doi: http://dx.doi.org/10.1177/036354659101900609

[21] Bynum, E.B., Barrack, R.L. \& Alexander, A.H., Open versus closed chain kinetic exercises after anterior cruciate ligament reconstruction. A prospective randomized study. The American Journal of Sports Medicine, 23, pp. 401-406, 1995. doi: http://dx.doi.org/10.1177/ $\underline{036354659502300405}$

[22] Zatsiorsky, V., Kinematics of human motion (Chapter 5). Kinematics of Individual Joints, ed. V. Zatsiorsky, Human Kinetics: Pennsylvania, pp. 282-285, 1998.

[23] Wilson, D.R., Feikes, J.D., Zavatsky, A.B. \& O'Connor, J.J., The components of passive knee movement are coupled to flexion angle. Journal of Biomechanics, 33, pp. 465-473, 2000. doi: http://dx.doi.org/10.1016/S0021-9290(99)00206-7

[24] LINK ${ }^{\circledR}$ Endo-Model Rotational Knee System, available at http://www.presearch.co.uk/assets/ newsplint/products/brochures/821005/Endo_Rotational_Knee_Implants_and_Instruments.pdf

[25] Biomet - Oxford Partial Knee, available at http://www.biomet.com/orthopedics/getFile. cfm? id $=2857 \& \mathrm{rt}=$ inline

[26] Csintalan, R.P., Schulz, M.M., Woo, J., McMahon, P.J. \& Lee, T.Q., Gender differences in patellofemoral joint biomechanics. Clinical Orthopaedics and Related Research, 402, pp. 260 269, 2002. doi: http://dx.doi.org/10.1097/00003086-200209000-00026

[27] Kirby, H., Shurman, J.R., Greene, K., McCarthy, J., Moskal, J., Hoeman, T. \& Mont, M.A., Anthropometric measurements of the human knee: correlation to the sizing of current knee arthroplasty systems. Journal of Bone \& Joint Surgery, 85, pp. 115-122, 2003.

[28] Burton, T.M.W., Vaidyanathan, R., Burgess, S.C., Turton, A.J. \& Melhuish, C., Sensitivity Analysis of a Parametric Hand Exoskeleton Designed to Match Natural Human Grasping Motion. Proceedings of TAROS, pp. 390-401, 2012.

[29] Chua, C.K., Leong, K.F. \& Lim, C.S., Rapid prototyping: principles and applications - 3rd edn. (Chapter 7). Applications and Examples, World Scientific Publishing Company Incorporated, pp. 360-395, 2010.

[30] Siston, R.A., Giori, N.J., Goodman, S.B. \& Delp, S.L., Surgical navigation for total knee arthroplasty: a perspective, Journal of Biomechanics, 40, pp. 728-735, 2007. doi: http://dx.doi. org/10.1016/j.jbiomech.2007.01.006

[31] Chauhan, S.K., Scott, R.G., Breidahl, W. \& Beaver, R.J., Computer-assisted knee arthroplasty versus a conventional jig-based technique - A randomised, prospective trial. Journal of Bone \& Joint Surgery, 86, pp. 372-377, 2004. doi: http://dx.doi.org/10.1302/0301-620X.86B3.14643

[32] Hart, R., Janecek, M., Chaker, A. \& Bucek, P., Total knee arthroplasty implanted with and without kinematic navigation. International Orthopaedics, 27, pp. 366-369, 2003. doi: http:// dx.doi.org/10.1007/s00264-003-0501-6

'This is a revised version of the paper published in WIT Transactions on Ecology and the Environment, Vol 160, (C) 2012 WIT Press, www.witpress.com, ISSN 1743-3541 (on-line), doi:10.2495/ DN120031'. 